\title{
"Combination of Fuel Cell and Wind Energy with Controlled Power Processing using Fuzzy Logic"
}

\author{
Chethan .H. R \\ Assistant Professor, E\&E Department, PESCE, Mandya, Karnataka, India
}

\begin{abstract}
Small scale technologies to produce electricity close to the end users of power are employed by Distributed generation approach. Renewable energy based Distributed generators produce electricity production with the decrease in the global warming. The renewable energy based distributed generators (DG's) based on wind, solar energy, biomass, mini-hydro along with use of fuel cells and micro turbines will give massive advantages in near future. Distributed generation powered by various renewable and non-conventional microsources has become an attractive option for configuring modern electrical grids because of its advantages like environmental friendliness, expandability and flexibility. A microgrid paves a way to effectively integrate renewable energy based distributed generation. The microgrid consists of cluster of loads and distributed generators that operate as a single controllable system. The microgrid can operated in parallel with or isolated from the main power grid. The microgrid concept introduces the reduction of multiple reverse conversions in an individual AC or DC grid and also facilitates connections to variable renewable $\mathrm{AC}$ and DC sources and loads to power systems. Concerned about safe operation and protection of equipment has risen by the interconnection of DGs to the utility/grid through power electronic converters. Enhancement of local reliability, reduction of feeder losses, local voltages support, increased efficiency through use of waste heat, correction of voltage sag or uninterruptible power supply are the special requirement of the customers, the microgrid can be designed to meet their special requirements. In the present work the performance of hybrid AC/DC microgrid system is analyzed in the grid tied mode. Here we have developed a microgrid by using fuel cell system, wind turbine generator and battery. Also fuzzy logic controllers along with PI control mechanisms are implemented for the converters to properly coordinate the AC sub-grid to DC sub-grid. The results are obtained using the MATLAB/ SIMULINK environment.
\end{abstract}

Index Terms: Renewable, Distributed Generator, Fuel, Wind, AC/DC Microgrid.

\section{INTRODUCTION}

Now electric distribution technology stepped into the next century, many trends are becoming noticeable that will change the requirements of energy delivery. These modifications are being driven from both the demand side and from the supply side. By deregulation and due to an increasing amount of distributed energy resources (DER) power systems currently undergo considerable change in operating requirements. In many cases DERs include different technologies that allow generation in small scale (microsources) and some of them take advantage of renewable energy resources (RES) such as solar, wind or hydro energy.

Having microsources close to the load has the advantage of reducing transmission losses as well as preventing network congestions. Moreover, the possibility of having a power supply interruption of end-customers connected to a low voltage $(\mathrm{LV})$ distribution grid is diminished since adjacent microsources, controllable loads and energy storage systems can operate in this landed mode in case of severe system disturbances. The distinctive micro grid has the similar size as a low voltage distribution feeder and will rare exceed a capacity of 1 MVA and a geographic span of $1 \mathrm{~km}$. Generally more than $90 \%$ of low voltage domestic customers are supplied by underground cable when the reset is supplied by overhead lines. The microgrid often supplies electricity and heat to the customers by means of combined heat and power plants (CHP), gas turbines, fuel cells, photovoltaic (PV) systems, wind turbines, etc. The energy storage systems usually include batteries and flywheels .The storing device in the microgrid is equivalent to the rotating reserve of large generators in the conventional grid which ensures the balance between energy generation and consumption especially during rapid changes in load or generation.

From the customer point of view, microgrids deliver both thermal and electricity requirements and in addition to improve local reliability, reduce emissions, improve power excellence by supportive voltage and reducing voltage dips and potentially lower costs of energy supply. From the utility viewpoint, application of distributed energy sources can potentially reduce the demand for distribution and transmission facilities. Distributed generation will reduce flows in transmission and distribution circuits with two important effects loss 
reduction and ability to potentially substitute for network assets because of the fact that distributed generation is always located near the load. In addition, as seen by end customers the presence of generation close to demand could increase service quality. In addition, as seen by end customers the presence of generation close to demand could increase service quality. The development of micro grids by using the availability and developing technologies for distributed generation units are based on renewable sources and micro sources that are characterized by very low emissions can contribute to the reduction of emissions and the mitigation of climate changes.

Improved energy efficiency, minimized overall energy consumption, reduced greenhouse gases and pollutant emissions, improved service quality and reliability, cost efficient electricity infrastructure replacement are various advantages offered by microgrids to end-consumers, utilities and society.

Ensuring stable operation during network disturbances, maintaining stability and power quality in the islanding mode of operation necessitates the improvement of sophisticated control strategies for microgrid's inverters in order to provide stable frequency and voltage in the presence of arbitrarily varying loads are the technical challenges linked with the operation and control of microgrids. The microgrid concept has stimulated many researchers and attracted the attention of governmental organizations in Europe, USA and Japan. There are various technical issues associated with the integration and operation of microgrids.

\section{A TYPICAL FYBRID AC/DC MICROGRID}

The hybrid microgrids consist of AC and DC grid interconnected with the bidirectional main converter and transformer. The three phase AC network of the hybrid grid is connected to the utility grid through a transformer and a circuit breaker. AC power sources wind turbine generator connected to the AC grid.AC energy storage devices such as fly wheels are connected to $\mathrm{AC}$ grid through converters. Fig1 shows a conceptual hybrid system configuration where various ac and dc sources and loads are connected to the corresponding $\mathrm{dc}$ and ac networks. The ac and dc links are connected together through two transformers and two four-quadrant operating three phase converters. The ac bus of the hybrid grid is tied to the utility grid.

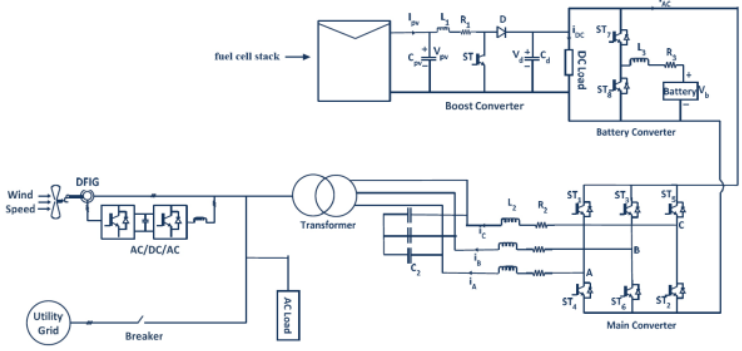

fig 1 Model for the booster and main converter.

\section{SYSTEM CONFIGURATION AND MODELING}

A . Grid configuration

A hybrid system is configuration of various ac and dc sources and loads that are connected to the corresponding $\mathrm{dc}$ and ac networks. The ac and dc links are connected together through two transformers and two four-quadrant operating three phase converters. The ac bus of the hybrid grid is tied to the utility grid. A compact hybrid grid as shown in Fig. 1 is modeled using the Simulink in the MATLAB to simulate system operations and controls.

Fuel cell are connected to dc bus through dc/dc boost converter to simulate dc sources. A capacitor is to suppress high frequency ripples of the output voltage. A $50 \mathrm{~kW}$ wind turbine generator (WTG) with doubly fed induction generator (DFIG) is connected to an ac bus to simulate ac sources. A battery is used as energy storage which is connected to dc bus through a bidirectional $\mathrm{dc} / \mathrm{dc}$ converter. Variable de load and ac load are connected to $\mathrm{dc}$ and ac buses respectively. The rated voltages for $\mathrm{dc}$ and ac buses are $400 \mathrm{~V}$ and $400 \mathrm{~V}$ rms respectively. A three phase bidirectional dc/ac main converter with R-L-C filter connects the dc bus to the ac bus through an isolation transformer. Here in the main converter the fuzzy logic along with PI control is implemented.

\section{B. Grid Operation}

The hybrid grid can operate in two modes. In grid-tied mode, the main converter is to provide stable dc bus voltage and required reactive power and to exchange power between the ac and dc buses. The boost converter and WTG are controlled to provide the maximum power. When the output power of the dc sources is greater than the dc loads, the converter acts as an inverter and injects power from dc to ac side. When the total power generation is less than the total load at the dc side, the converter injects power from the ac to dc side. When the total power generation is greater than the total load in the hybrid grid, it will inject power to the utility grid. Otherwise, the hybrid grid will receive power from the utility grid. In the grid tied mode, the battery converter is not very important in system operation because power is balanced by the utility grid. In autonomous battery play a prominent role. DC bus voltage is maintained stable by a battery converter or boost converter according to different operating conditions. The main converter is controlled to provide a stable and high quality bus voltage. Both fuel cell and WTG can operate on system operating requirements.

C. Modelling of Wind Turbine Generator Power output from a WTG is determined

$$
\mathrm{P}=\frac{1}{2} \rho \mathrm{A}\left(\mathrm{V}_{\infty}\right)^{3}
$$

Where, $\mathrm{P}$ is power in watts $(\mathrm{W}), \rho$ is the air density in kilograms per cubic meter $\left(\mathrm{kg} / \mathrm{m}^{3}\right)$, $A$ is the swept rotor area in square meter $\left(\mathrm{m}^{2}\right)$.

The mathematical models of a DFIG are essential requirements for its control system. The voltage equations 
of an induction motor in a rotating - coordinate are as follows:

$$
\begin{aligned}
& {\left[\begin{array}{l}
u_{v d s} \\
u_{v g} \\
u_{v d} \\
u_{v g}
\end{array}\right]=\left[\begin{array}{cccc}
-R_{s} & 0 & 0 & 0 \\
0 & -R_{s} & 0 & 0 \\
0 & 0 & R_{g} & 0 \\
0 & 0 & 0 & R_{y}
\end{array}\right]\left[\begin{array}{l}
i_{d s} \\
i_{q s} \\
i_{d r} \\
i_{q v}
\end{array}\right]} \\
& +p\left[\begin{array}{c}
\lambda_{w \sigma} \\
\lambda_{q s} \\
\lambda_{w} \\
\lambda_{q p}
\end{array}\right]+\left[\begin{array}{c}
-w_{1} \lambda_{q s} \\
w_{1} \lambda_{d s} \\
-w_{2} \lambda_{q r} \\
w_{2} \lambda_{w}
\end{array}\right] \\
& {\left[\begin{array}{l}
\lambda_{d s} \\
\lambda_{q s} \\
\lambda_{d r} \\
\lambda_{q g}
\end{array}\right]=\left[\begin{array}{cccc}
-L_{s} & 0 & L_{m} & 0 \\
0 & -L_{s} & 0 & L_{m} \\
-L_{m} & 0 & L_{r} & 0 \\
0 & -L_{m} & 0 & L_{r}
\end{array}\right]\left[\begin{array}{l}
i_{d s} \\
i_{q s} \\
i_{d r} \\
i_{q q}
\end{array}\right] .}
\end{aligned}
$$

The dynamic equation of the DFIG

$$
\begin{aligned}
& \frac{I}{n_{p}} \frac{d w_{r}}{d t}=T_{\mathrm{m}}-T_{e} \\
& T_{e}=n_{p} L_{m}\left(i_{q s} i_{d r}-i_{d s} i_{q r}\right)
\end{aligned}
$$

Where, the subscripts $\mathrm{d}, \mathrm{q}, \mathrm{s}$, and $\mathrm{r}$ denote d-axis, q-axis, stator, And rotor respectively, $\mathrm{L}$ represents the inductance, $\lambda$ is the flux linkage, $u$ and $i$ represent voltage and current respectively, $\boldsymbol{\omega}_{1}$ and $\boldsymbol{\omega}_{2}$ are the angular synchronous speed and slip speed respectively, $\mathrm{T}_{\mathrm{m}}$ is the mechanical torque, $\mathrm{T}_{\mathrm{e}}$ is the electromagnetic torque.

If the synchronous rotating $\mathrm{d}-\mathrm{q}$ reference is oriented by the stator voltage vector, the $\mathrm{d}$-axis is aligned with the stator voltage vector while the q-axis is aligned with the stator flux reference frame. Therefore, $\lambda_{\mathrm{ds}}=0$ and $\lambda_{\mathrm{qs}}=\lambda_{\mathrm{s}}$

\section{Modelling of Battery}

Two important parameters to represent state of a battery are terminal voltage and state of charge (SOC) as follows:

$$
V_{b}=V_{o}+R_{b} i_{b}-K \frac{Q}{Q+\int i_{b} d t}+A \cdot \exp \left(B \int i_{b} d t\right)
$$

$$
\mathrm{SOC}=100\left(1+\frac{\int i_{b} d t}{Q}\right)
$$

Where, $R_{b}$ is internal resistance of the battery, $V_{O}$ is the open circuit voltage of the battery, $i_{b}$ is battery charging current, $\mathrm{K}$ is polarization voltage, $\mathrm{Q}$ is battery capacity, $\mathrm{A}$ is exponential voltage, and is exponential capacity.

\section{E. Modelling Of Fuel Cell}

A fuel cell is a device that converts chemical energy from fuel into electric energy with the help of anode, cathode and an electrolyte. In this work, Solid oxide fuel cell is used and it uses solid oxide as an electrolyte.

\section{COORDINATION CONTROL OF THE CONVERTERS}

There are five types of converters in the hybrid grid. Those converters have to be coordinately controlled with the utility grid to supply an uninterrupted, high efficiency, and high quality power to variable dc and ac loads under variable wind speed when the hybrid grid operates in both isolated and grid tied modes

When the hybrid grid operates in grid tied mode, the control objective of the boost converter is to track its terminal voltage. The back-to-back ac/dc/ac converter of the DFIG is controlled to regulate rotor side current to synchronize with ac grid. The energy surplus of the hybrid grid can be sent to the utility system. The role of the battery as the energy storage becomes less important because the power is balanced by the utility grid. In this case, the only function of the battery is to eliminate frequent power transfer between the dc and ac link. The $\mathrm{dc} / \mathrm{dc}$ converter of the battery can be controlled as the energy buffer using the technique. The main converter is designed to operate bidirectional to incorporate complementary characteristic of wind and fuel sources. The control objectives of the main converter are to maintain a stable dc-link voltage for variable dc load and to synchronize with the ac link and utility system.

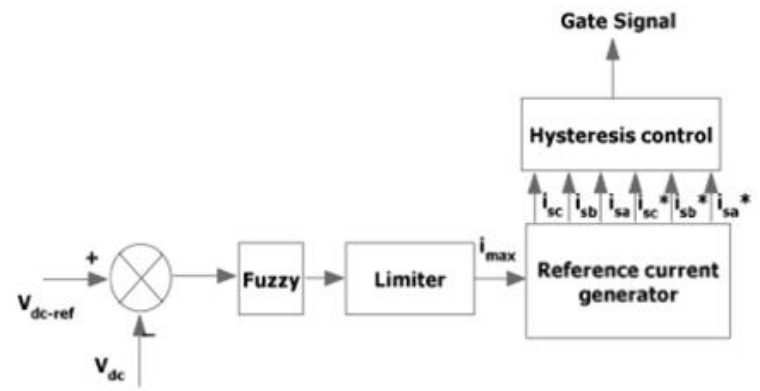

fig 2 Conventional Fuzzy Controller

Fig 2 shows the internal structure of control circuit. The control scheme consist of a fuzzy controller, alimiter and three phase sine wave generator for reference current generation and generation of switching signals. The peak value of reference current is estimated by regulating DC link voltage. The actual capacitor voltage is compared with a set reference value.The error signal is then processed through a fuzzy controller which contribute to zero steady state error in tracking the refernce current signal. The control scheme for controlling the main converter during grid tied mode of operation is shown. For smooth power exchange between the AC and DC grids and to supply the necessary reactive power $\mathrm{dq}$ control is used for controlling main converter along with fuzzy control. The DC bus voltage is maintained to constant value with fussy logic along with PI control. Output of the de link voltage loop through fuzzy logic controller is set as an active current reference $\left(i_{d} *\right)$ and reactive current reference $\left(i_{q} *\right)$ is set to 
zero. The active current (id) and reactive current (iq) is calculated through Clarke and park transformation.

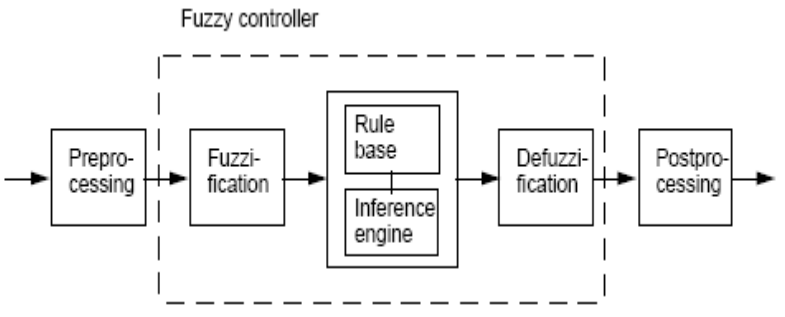

fig 3 Block diagram of fuzzy logic controller

In construction of fuzzy logic control, the Fuzzy Logic Toolbox allows us to create and edit fuzzy inference systems. One can create these systems using graphical tools or command-line functions, or one can generate them automatically using either clustering Fuzzy techniques. There are five primary GUI tools for building, editing, and observing fuzzy inference systems in the Fuzzy Logic Toolbox

i.e. The Fuzzy Inference System or FIS Editor, Membership Function Editor, Rule Editor. Rule Viewer, Surface Viewer. To demonstrate the fuzzy logic control capabilities of MATLAB we will simulate the example. We will use the same input and output membership functions; A1, A2, B1 and B2. To begin, we will define a Simulink model that will be used to run the simulation. Open MATLAB and Simulink and create a new file. Add a ramp input, Scope, and Fuzzy Logic Controller with Rule viewer to the file as shown. The Fuzzy Logic Controller with Rule viewer block can be found in the fuzzy logic toolbox or by typing the name in the search box of the Library Browser.

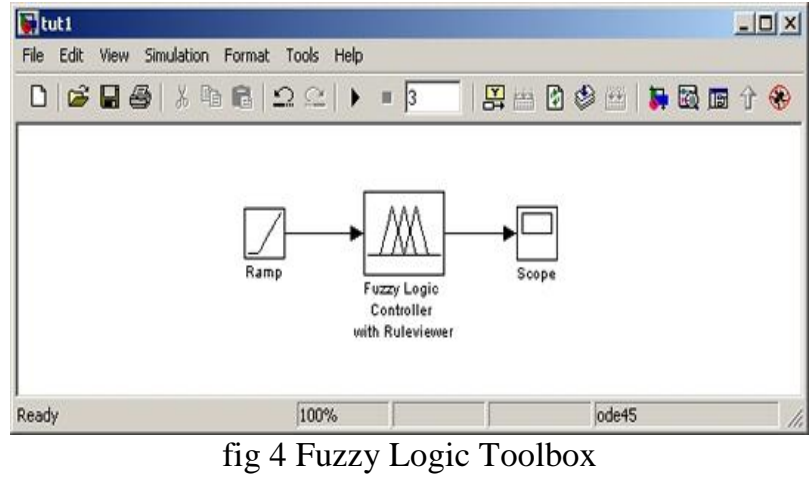

Once our simulink file has been created as shown above .We will save the file, for example the file name used is tut1. Now that the overall system has been defined the fuzzy controller needs to be designed. To do this the Fuzzy Inference System (FIS) editor will be used. To open a new FIS file with the FIS editor, type the following into MATLAB:

$>$ fuzzy

The following window will open; it is the Fuzzy Inference System editor. With the FIS editor the input and output membership functions can be defined, the rule base is defined, and the fuzzy operators are set.

The default system has one input and one output and uses the Mamdani inference and aggregation method. It also illustrates the three aspects of a fuzzy controller; fuzzification, inference, and defuzzification. To begin, let us define the membership functions. Double click on the yellow input box and you will be brought to the membership function editor.

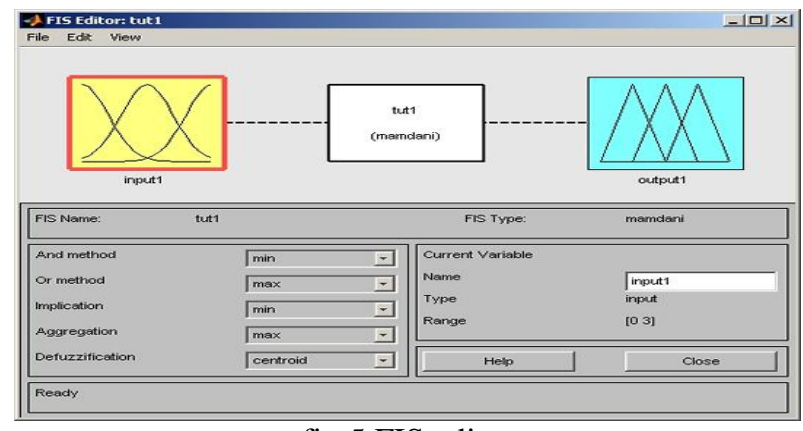

fig 5 FIS editor

Once the FIS file is created the file has to be import from file and explain it has to be export to the work space . In creating FIS file, the membership function editor defines the number of input and output of the system .In my work i have considered two input and one output.The input range should be defined an even the output change should be defined .The membership function editor can now be closed to return to the FIS editor. The FIS now needs to have rules defined. To do this double click on the white box in between the input and output membership functions. This will bring up the Rule Editor, this is where the linguistic inference rules are entered. These rules are defined using the fuzzy membership functions labels A1, A2, B1, and B2. To enter a rule select the desired 'if' option and 'then' option and click 'add rule' at the bottom. The rules should be defined.. This window can be closed and now the FIS is finished, it only needs to be exported to the Simulink model. To do this from the FIS editor, under File the Export and then To Workspace... and enter the name of the Simulink model in the Workspace Variable field, for this case it is 'tut1'. Now, in Simulink, double click on the Fuzzy logic controller and set the FIS matrix to tut 1 and change the refresh rate to 0.01. Now the simulation can be run for 3 seconds. While the simulation is running the Rule Viewer window will appear. The Rule Viewer window shows the relevant input and output membership functions for each rule.

\section{SIMULATION AND RESULTS}

The simulation of the hybrid micro grid is carried out using MATLAB/ Simulink package. The proposed hybrid micro grid system is simulated. A fuel cell stack and wind turbine generator is taken. The proposed system is controlled to operate in grid tied mode and battery is assumed to be fully charged. A hybrid microgrid is 


\section{IJIREEICE \\ International Journal of Innovative Research in Electrical, Electronics, Instrumentation and Control Engineering \\ ISO 3297:2007 Certified \\ Vol. 5, Issue 2, February 2017}

simulated using MATLAB/SIMULINK environment. The operation is carried out for the grid connected mode. Along with the hybrid microgrid, the performance of the doubly fed induction generator, fuel cell system is analyzed. The fuel cell, battery and wind speed are also taken into consideration for the study of hybrid microgrid. The performance analysis is done using simulated results which are found using MATLAB.

The various characteristics of the hybrid microgrid are represented by the figures. Here the microgrid operates in the grid tied mode. In this mode, the main converter operates in the DQ mode and power is balanced by the utility grid. The battery is fully charged. AC bus voltage is maintained by the utility grid and DC bus voltage is maintained by the main converter.

In grid connected mode, main converter is controlled through dq control and following results are obtained. The figure 8 represent the grid power in which the fuzzy controller has shown better setting values .It also showing a lesser peak overshoot compared to PI controller.

When the AC side is loaded heavily, then there will be a power demand on the $\mathrm{AC}$ side and so the excess power on the DC grid will be transferred to AC grid. When DC grid is loded heavily, then there will be power demand on the DC grid. The power on grid has negative value. As the fuel cells are constant DC power source, it can be used with WTG to manage heavier loads on AC side during low wind speed.

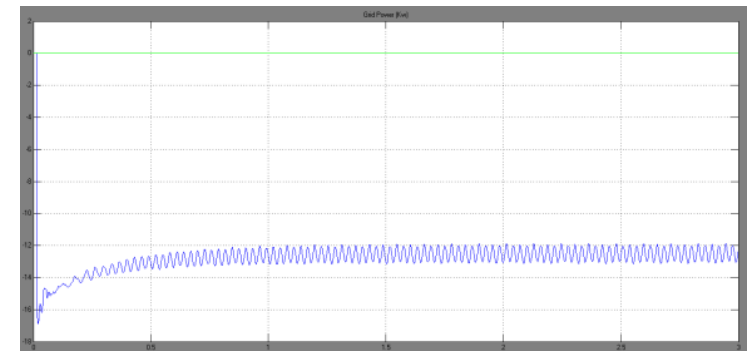

fig 6 Power Of The Grid

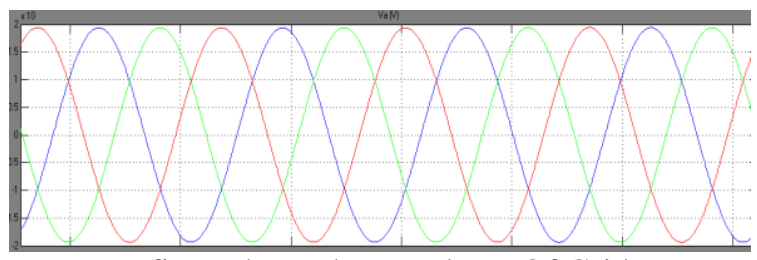

fig 7 Three Phase Voltage Of Grid

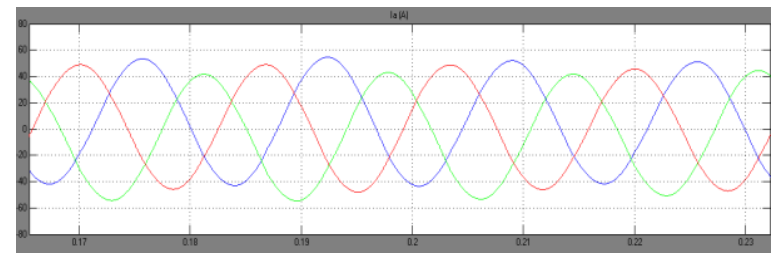

fig 8 Three Phase Current Of Grid

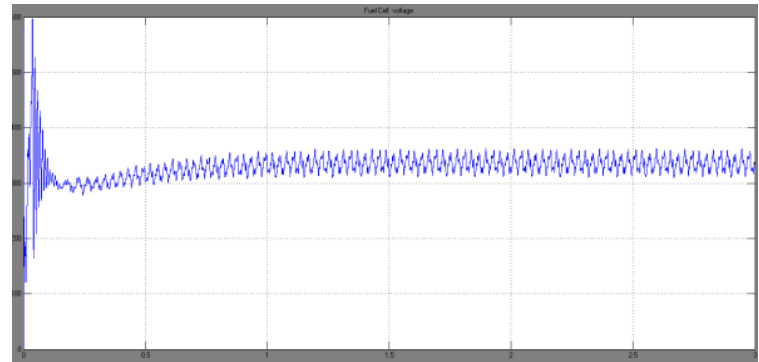

fig 9 Fuel Cell Voltage

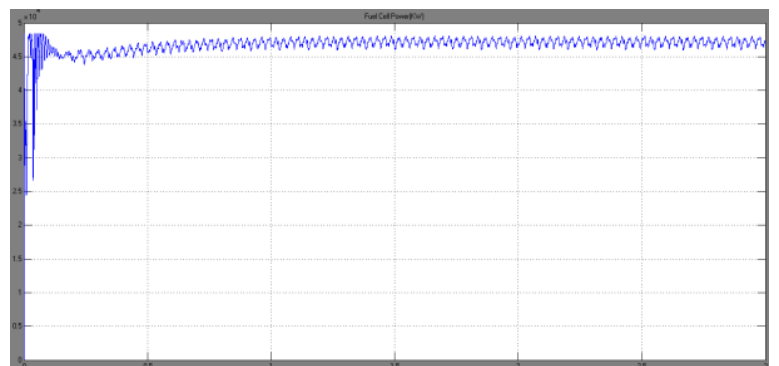

fig 10 Fuel Cell Power

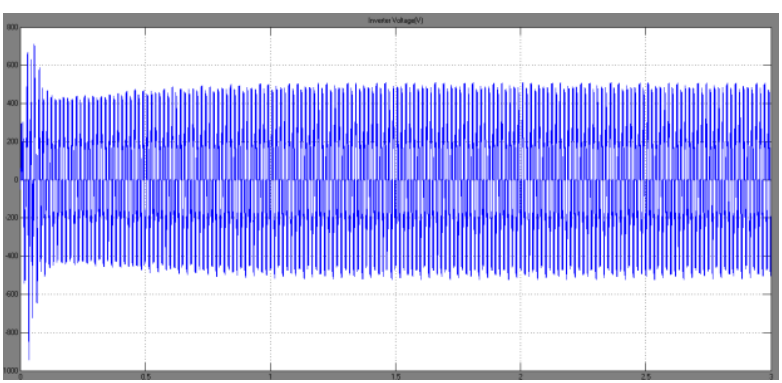

fig 11 Inverter Voltage

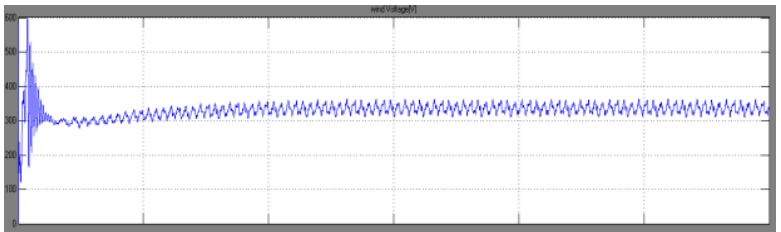

fig 12 Wind Voltage

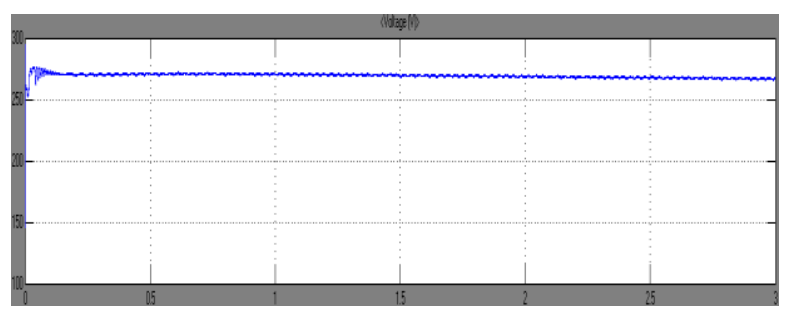

fig 13 Voltage Of Battery

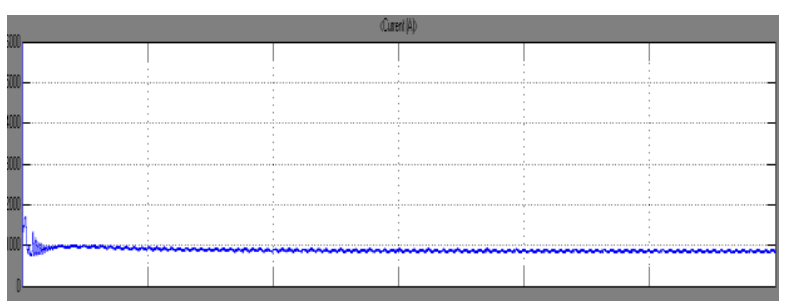

fig 14 Current Of Battery 


\section{CONCLUSION}

The modeling of hybrid microgrid for power system configuration is done in MATLAB/SIMULINK environment. The present work mainly includes the grid tied mode of operation of hybrid grid. The models are developed for all the converters to maintain stable system under various loads and resource conditions and also the control mechanism are studied. The maximum power from DC sources and to coordinate the power exchange between DC and AC grid is studied. Although the hybrid grid can reduce the processes of $\mathrm{DC} / \mathrm{AC}$ and $\mathrm{AC} / \mathrm{DC}$ conversions in an individual $\mathrm{AC}$ or $\mathrm{DC}$ grid, there are many practical problems for the implementation of the hybrid grid based on the current AC dominated infrastructure. The efficiency of the total system depends on the diminution of conversion losses and the increase for an extra DC link. The hybrid grid can provide a reliable, high quality and more efficient power to consumer. The hybrid grid may be feasible for small isolated industrial plants with both Fuel cell systems and wind turbine generator as the major power supply

The PI controller being the traditional controller would help in controlling some parameters for a desired output to be obtained. But the controller has the peak overshoot that could not be reduced much by variation of the $\mathrm{Kp}, \mathrm{Ki}$ and $K_{d}$ parameters. So the fuzzy logic controller has to be used in order to get rid of the peak overshoot and the delayed settling time. This paper is defined with the problem of analyzing the PI and the Fuzzy controller in the hybrid system which include the wind and the fuel cell generator connected to the grid for synchronization purpose using the $\mathrm{d}-\mathrm{q}$ method. The present work mainly includes the grid tied mode of operation of hybrid grid. The models are developed for all the converters to maintain stable system under various loads and resource conditions and also the fuzzy logic control mechanism are studied.. The hybrid grid can provide a reliable, high quality and more efficient power to consumer. The hybrid grid may be feasible for small isolated industrial plants with both fuel cell systems and wind turbine generator as the major power supply.

\section{REFERENCES}

[1] Xiong Liu, Peng Wang, and Poh Chiang Loh, "A hybrid AC/DC microgrid and its coordination control," IEEE Trans. Smart Grid, vol. 2, pp. 278-286 June. 2011.

[2] F. D. Kanellos, A. I. Tsouchnikas, N. D. Hatziargyriou, "MicroGrid simulation during grid-connected and islanded modes of operation", International Conference on Power Systems Transients (IPST 05) in Montreal, Canada on June 19-23, 2005.

[3] Ramon Zamora, Anurag K. Srivastava, "Controls for microgrids with storage: Review, challenges, and research needs", Renewable and Sustainable Energy Reviews, Volume 14, Issue 7, pp. 20092018 September 2010.

[4] Arulampalam, N. Mithulananthan, R.C. Bansal, and T.K. Saba, "Micro-grid control of PV-Wind-Diesel hybrid system with islanded and grid connected operations," in Proc. IEEE Int. Conf. Sustainable Energy Technologies, pp. 1-5, Dec. 2010.

[5] M. Barnes, J. Kondoh, H. Asano, and J. Oyarzabal, "Real-World microGrids- An overview," in IEEE Int. Conf. Systems of Systems Engineering,pp.1-8, April 2007.
[6] J.Lee, B.Han, Y.Seo, "Operational analysis of DC Micro-grid using detailed model of distributed generation," Energy Conversion Congress and Exposition (ECCE), pp.3153-3160, 12-16 Sept. 2010

[7] Guiting Xue, Yan Zhang, Dakang Zhu, "A distributed control strategy for an isolated residential DC microgrid," Research Journal of Applied Sciences, Engineering and Technology vol.4, Issue 20 pp. 4138-4144, Oct. 2012.

[8] Yinjiao Xing, Eden W.M.Ma, Kwok L.Tsui and Michael Pecht, "Battery management systems in electric and hybrid vehicles," Energies, vol. 4,Issue 11, pp. 1840-1857, Oct. 2011.

[9] Balasubramaniam Babypriya and Rajapalan Anita, "Modeling, simulation and analysis of doubly fed induction generator for wind turbines," Journal of Electrical Engineering, Vol.60, No.2, pp. 79$85,2009$.

[10] Tremblay O, Dessaint L.A, Dekkiche A.I, "A Generic Battery Model for the Dynamic Simulation of Hybrid Electric Vehicles," Vehicle Power and Propulsion Conference, pp.284-289, Sept. 2007.

[11] Liping Su, Guojie Li, Zhijian Jin, "Modeling, control and testing of a voltage-source- inverter-based microgrid," Electric Utility Deregulation and Restructuring and Power Technologies (DRPT), 4th International Conference on, pp.724-729, 6-9 July 2011.

[12] M. H. Nehrir and C. Wang, "Modeling and control of fuel cells: distributed generation applications," Wiley-IEEE Press, February 2009.

[13] C. Boccaletti, G. Duni, G. Fabbri, E. Santini, "Simulation models of fuel cell systems," ICEM 2006 - 17th Int. Conf. on Electrical Machines, China (Greece), 2006

[14] Adrea Junyent, Oriol Gomis-Bellmunt, Andreas Sumper, Marc Sala, "Modeling and control of the doubly fed induction generator wind turbine," Simulation modeling practive and theory, vol. 18, Issue 9, pp. 1365-1381 October 2010.

\section{BIOGRAPHY}

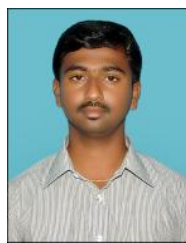

Chethan H R completed his Engg. from DBIT Bangalore and Masters from ACTS Hyderabad. Working as Asst. Professor in E\&E Department, PESCE, Mandya, Karnataka, India from 2015. 